\title{
Exploring the consistency, transparency and portability of dental technology education: Benchmarking across Norway, Ireland and Australia
}

Myhrer, T., Evans, J. L., Haugen, H., Gorman, C., Kavanagh, Y. \& Cameron, A. 2015. Exploring the consistency, transparency and portability of dental technology education: Benchmarking across Norway, Ireland and Australia. European Journal of Dental Education, doi: 10.1111/eje.12160.

\begin{abstract}
Dental Technology programs of study must prepare students to practice in a broad range of contemporary workplaces. Currently there is limited evidence to benchmark dental technology education - locally, nationally or internationally. This research aims to improve consistency, transparency and portability of dental technology qualifications across three countries. Data was accessed from open source curriculum documents and five calibrated assessment items. Three institutions collaborated - Oslo and Akershus University College, Norway; Trinity College Dublin, Ireland and Griffith University, Australia. From these, 29-44 students completed 174 assessments. The curricula reflect the community needs of each country and display common themes that underpin professional dental technology practice. Assessment results differed between institutions but no more than a normal distribution. Face-to-face assessment moderation was critical to achieve consistency. This collaborative research has led to the development of a set of guidelines for other dental technology education providers interested in developing or aligning courses internationally to enhance portability of qualifications.
\end{abstract}

\section{KEY WORDS}

Dental Technology, Education, Assessment, Curriculum. International, Knowledge, Skills, Abilities. Mobility

\section{INTRODUCTION}

Dental technology programs of study must prepare students to practice in a broad range of real-world workplaces. Graduates need to contribute, and collaborate within a global work context (1). There is limited evidence to benchmark dental technology education -locally, nationally or internationally. Good practice around teaching, 
learning and ultimately assessment are paramount to ensure that students attain the knowledge, skills and attributes required to meet national and international standards (2). A major requirement in dental technology education is the need for students to obtain contemporary scientific knowledge and develop excellent psychomotor skills while becoming lifelong learners through critical thinking and self-assessment. Ideally, qualifications should be consistent, transparent and portable across institutions. This was one of the key objectives of the Bologna Declaration of June 1999 (3). The European Credit Transfer and Accumulation System (ECTS), is an academic credit system based on the estimated student workload required to achieve recognition for periods of study, to facilitate student mobility, credit accumulation and transfer (3). Qualifications should be a reliable measure of graduate capabilities and readiness to practice $(4,7-9)$. Validation and moderation of dental technology qualifications is required internationally so that the learning outcomes are relevant and clearly expressed to the professional stakeholders (students, graduates, education providers, employers, health departments and regulation agencies) $(4,5)$. Academic mobility between countries for faculty and students is highly desirable for opportunities to seek future education or employment. To this end ideally transparent dental technology qualifications are required internationally.

Dental technology training and indeed the requirement for registration with a recognised authority varies greatly globally. In Norway, registration is strictly required for practising dental technicians, in Ireland and Australia no registration is required despite ongoing lobbying of their national dental technology associations. In Queensland, Australia, registration was revoked in 2013 (6) due to the recategorisation of government health care professions (7). In the UK, registration of dental technicians, accreditation of education and continuing professional development became mandatory in 2008 (8). Certification is required in the USA (9) and in Canada, dental technology is strongly regulated throughout the majority of States (10). In China there is very little regulation of the profession or standardisation of education (11).

Government regulatory authorities are responsible for the safety of the patient and in doing so, registration of dentists is clearly paramount, however, the rather haphazard approach to the registration of dental technicians and accreditation of education programmes, across different countries has cause for concern. This has never been more apparent than of late, where a global trend of sending work 'offshore' has 
developed (8). In Norway and the UK, dental laboratory owners are required to be registered; however, laboratory assistants do not require registration. There is a 'loop hole' which exists whereby dentists or laboratory owners may send send work 'offshore' to unregistered dental laboratories causing concern around quality assurance standards $(8,12)$.

The scope of practice for dental technicians in most countries is often defined by the legislation that governs the needs and requirements of practicing dentists. However there are guiding principles that dental technology educators should aspire to (13). While the education of dental technicians has become more formalised and in many cases is now part of a university system, it has not been followed through with appropriate accreditation nor registration. In some countries government funding determines the various models for dental technology education such as: apprenticeship, certificate, diploma, degree and higher level. It is critical that dental technology curricula be evaluated to establish international standards that support mobility, further education and potentially guide others.

The current study involved three dental technology Baccalaureate programs from Oslo and Akershus University College (OAUC - level 6 NQF - Norway), Trinity College Dublin (TCD - level 7 NQAI - Ireland) and Griffith University (GU - level 7 AQF - Australia). The TCD and GU curricula are designed to enhance interprofessional education in the oral health care team (OHCT) where dentistry students and dental technology students learn 'from', 'with' and 'about' each other (13). The comparison of curricula and consequential alignment should allow students and graduates to have enhanced opportunities to access dental technology undergraduate and post-graduate education which lead to flexible opportunities for future study and/or employment. These opportunities may lead to increased possibilities for continuing professional development and enhance the likely hood of lifelong learning (14). The national qualification documents serve as a translation device to improve understanding and readability of qualifications across different countries and systems, and thus promote lifelong and life-wide learning (15-17). Qualifications from the three educational programs were validated across the three countries, and the learning outcomes clearly expressed. The dental technology curricula across all three countries include teaching, learning and assessment strategies associated with theoretical knowledge, practical skills and developing attitudes. These core program themes should be aligned with international quality 
assurance agencies (18-21), this is one of the Threshold Learning Outcomes (TLO) for health, Australian Learning and Teaching Academic Standards (LTAS) project to enable Educational Quality Assurance and accreditation (22). Results of practical assessment would provide a common 'base line' for key aspects of dental technology education.

\section{Aims and Scope of Research}

This project sets out to ascertain the consistency, transparency and portability of dental technology qualification across Norway (OAUC), Ireland (TCD) and Australia (GU) $(3,17,19,20)$. The first objective was to compare similarities and differences in curricula by analysing the strengths and exploring areas for development across the three dental technology programs that contribute to attaining learning outcomes consistent with EQF and AQF. The second objective was to benchmark grading systems (academic levels) across the three institutions so that results could be categorised for comparative purposes. This grading system could potentially provide a useful guide for other dental technology programmes. The third objective was to develop specific guidelines for other dental technology education providers on how a curriculum could be designed or modified in order to promote internationally recognised qualifications.

\section{METHODS}

\section{Preliminary pilot testing}

A pilot study was conducted in 2011-12 which measured OAUC and TCD students' levels of attainment consistent with EQF parameters in the application of psychomotor skills by conducting identical tests. The tests included common technical tasks in fixed and removable prosthodontics but not removable partial dentures or orthodontics due to the difference in time spent on 'teaching and learning' in this area. The project was subsequently extended to include the Australian partnership (GU) and AQF standards. Assessment criteria, distribution of grades and weighting for specific criteria, were modified as a result of the pilot study to improve criteria detail, readability and consistency. The duration required for each 'practical assessment' was deemed to be in accordance with the students' ability. All assessments were 'double blind marked' for moderation purposes and calibration of assessors was achieved (5). OAUC and TCD student participants in the pilot study differed from the final 2013 project. 


\section{Final project}

The research was conducted at OAUC (Norway), TCD (Ireland) and GU (Australia). Data was obtained from English written open source curriculum documents, five assessment calibration items (designed and piloted by OAUC and TCD) which were underpinned by the dental technology academics experiences and reflections. All data was collected during the semester timetable in 2012 and 2013. No participant identifiable information was recorded, stored or published.

Curricula and program documents were systematically evaluated, aligned to TLO's, analysed and mapped (23). This was then tabulated into a spread-sheet using Microsoft $^{\circledR}$ Excel $^{\circledR}$ version 14.3.6 (Redmond, WA, USA), to establish a baseline, explore similarities and differences in curricula and develop guidelines for modifying curricula.

The assessments were carried out at the predetermined timetabled assessment time for each course when each group had similar theoretical and practical training (24). The assessors from Norway and Ireland moderated assessment at both institutions, whereas the Australian assessors communicated via email to check for consistencies. Although, a later on-site moderation meeting took place between OAUC and GU assessors, to validate assessment results. Practical assessment items for tooth morphology (item 1), wax registration rims (item 2), gold crown wax-up (item 3), all ceramic crown (item 4) and complete denture set-up (item 5) were established using the same prosthetic models and marking criteria across all institutions (see Appendix 1). This quantitative data was analysed using 2011 Microsoft $^{\circledR}$ Excel $^{\circledR}$ (Redmond, WA, USA) version 14.3.6.

Reflections from the teaching teams at each institution were collated in 2013, when OAUC researchers visited TCD and the GU simultaneously; meetings were conducted using electronic sources to gain a better understanding of the academics experiences (25). These findings are incorporated into the discussion section.

\section{Participants}

Participants included all students who had completed the appropriate course for the designated assessment items. This included students enrolled in the first and second year of the Bachelor of Dental Technology (OAUC and TCD) and $1^{\text {st }}$ and $3^{\text {rd }}$ years of the Bachelor of Oral Health in Dental Technology (GU). OAUC student numbers range from 16-19 in second and third year - there was no intake for 2013. TCD had 6 students in first and final year and 5 in second year. GU had 16-23 students enrolled 
in first year and 13 in second and third year. Two academics from each institution participated in curricula analysis, preparation and assessment.

\section{RESULTS}

\section{Curriculum Analysis}

Threshold Learning Outcomes (TLO) (22) were aligned to the core program themes (Table 1). These core elements are displayed however the amount of learning differed. At, OAUC, TCD and GU dental technology students complete a module/unit of study of work integrated learning (WIL) or case studies (OAUC) where they learn with other health care students to enhance graduate attributes and employability. Removable partial denture and orthodontic technology is covered in theoretical and practical education across all institutions but to a lesser extent at OAUC. Fixed prosthodontics is taught more intensively at OAUC $\left(4^{\text {th }}\right.$ semester and further on $)$ than it is in GU and TCD.

The overall yearly percentage of hours allocated to learning practical skills between institutions (Table 2) was higher in first and second year at GU and highest in TCD in third year. Table 3 shows a comparison of the average number of timetabled teaching hours applied to a variety of teaching methods between the three institutions.

Table 4 presents a summary of methods for assessing knowledge, skills and attitudes across the three institutions. Assessment methods differed slightly - GU did not use oral or open book exams. Multiple-choice questions (MCQ's) are used at TCD and GU in first year health science courses, but not in OAUC. Otherwise OAUC and GU are quite similar in their approach to assessment methods and have more variety than TCD.

\section{Result of Student Assessments}

The total number of students who participated in the 5 assessment items, ranged from 29 - 44 (33 OAUC, 11 TCD, 36 GU). Table 5 demonstrates the number of students who attempted each assessment item, 174 assessment items were completed. The majority of students were female (66\% OAUC, 81\% TCD, 74\% GU Female). After calibration of the six authors across the three institutions (on-site), most assessment items were shown to be in a similar range of percentage scores for each assessor. Calibration between OAUC and GU was not ideal as it was conducted electronically, whereas face-to-face meetings clarified inconsistencies. Assessment scores varied across institutions. Overall the largest range of scores is seen in 
Assessment item 1, but it was the most successful. All TCD students achieved $80 \%$ and above. Assessment item 2 had the poorest results and the most varied range of scores between the institutions. Whereas assessment items 3,4 and 5 display a consistency between groups, with the majority of students achieving 60-79\% (Figure $1)$.

\section{Results of Student Assessment}

\section{Assessment Item 1 -Tooth Morphology}

Overall the premolars were the most common tooth to be positioned incorrectly, although some students confused the upper and lower molars as well. This was the most successful assessment item, overall 84\% (OUC 10/16, TCD 5/5 GU 22/23) of students scored above $60 \%$. The TCD students were ranked within the two highest categories (100-80\% range). OAUC were clustered between $99-40 \%$, and GU had the broadest spread of scores from 20-100\%. More OAUC students were in the lower range of scores.

\section{Assessment Item 2 - Registration Rims}

Registration rims had the widest variety of scores across all three institutions; OAUC and GU scores were spread across 4 percentage ranges and TCD across 3. Some OAUC students had problems with adaption to the sulcus area, while most of TCD students set the rim off the centre of the ridge and GU students experienced inconsistencies with adaptation to the fitting surface. So there was a range of discrepancies across all groups.

\section{Assessment 3 - 36 Gold Crown Wax-Up}

Overall marginal errors were the predominate inconsistency with the gold crown waxup. This assessment item scored the highest percentage score overall, 64\% (OUC 9/19, TCD 2/5, GU 10/13) of students scored above 60\%. One student from OAUC was in the lowest range.

\section{Assessment 4 - 21 All-Ceramic Crown}

The all-ceramic crown assessment item had the most number of required assessment criteria. Difficulties were experienced with ideal marginal ridge heights and marginal fit. This was the second most successful assessment, 81\% (OUC 5/7, TCD 3/6, GU 13/13) of all students scored above $60 \%$. All the GU students were in the same range, almost three quarters of OAUC were and half of TCD recorded similar. All ceramic crowns are included in the fixed prosthodontics 'stream' for OAUC students. One student from OAUC was in the lowest range. 


\section{Assessment 5 - Complete Denture Set Up}

The complete denture set up proved challenging in areas of achieving a balanced occlusion and positioning the lower anterior teeth to achieve the ideal over bite/over jet relationship. Overall 72\% (OUC 6/7, TCD 1/6, GU 14/16) of students scored over $60 \%$. One student from OAUC was in the lowest range. Complete denture set up is included in the removable prosthodontics 'stream' for OAUC students. All GU and TCD students are exposed to clinical teaching.

\section{DISCUSSION}

The results of curricula analysis and student testing integrated with reflections from researchers highlight the complexity of achieving international consistency, transparency of curriculum and enhancing the portability of qualifications. Although there is a modest number of dental technology students enrolled across the three institutions, this reflects the profession in all three countries, and are similarly represented world-wide (11). Dental technology is a technically significant area of prosthetics and oral health care, so it requires 'quality' not necessary a 'quantity' of dental technologists to perform the role. A balance between theoretical knowledge and practical application is needed to achieve a deep understanding (26). All three curricula have strategies and a 'philosophical standpoint' to engage students in the reflective process to develop 'life long learning' practices required in EQF and AQF standards. It is desirable that formal education is consistent, that the curricula are transparent, and that the institutions offering dental technology education are coherent in their approach. This will allow increased portability of suitable qualifications for students and a broader educational context for faculty.

\section{International consistency}

From a revision of the curricula, site visitations, student learning experience and assessment, there appears to be common core themes aligned to EQF and AQF standards. All curricula attempted to address treatment needs and stakeholder requirements within individual jurisdictions. TCD complete similar hours of study to that of GU students, however TCD do slightly more laboratory practice. OAUC spend more time on theoretical learning than TCD or GU. Perhaps OAUC spend too little time at the on-site laboratory to provide the ideal practical experience. However, by including a 'streamed' elective (fixed or removable prosthodontics), 
students can immerse themselves fully in their chosen area of study. Results show this has a positive influence on student results.

All three programs embrace and facilitate student-centred and didactic learning. The curriculum at OAUC provides the most time for self-study with a minimum of practical demonstrations compared with GU and TCD, Whereas, TCD and GU academics take a more active role, which may hinder students ability to self-reflect and be responsible for their own learning. However due to the proximity of the academic to the dental technology student and the time spent in the laboratory a close relationship is formed and learning needs are more easily detected in small class sizes - across all three institutions. There is an expectation that students need to take responsibility for self-learning to encourage a culture of life-long learning, this is more achievable in the student centred learning environment, where a greater emphasis is placed on interaction $(27,28)$.

\section{Transparency of curriculum}

The curricula were comprehensive and unambiguous, initially informed by stakeholders, and aim to develop students' knowledge, skills and attitude. Program learning outcomes and assessment expectations have common themes around producing competent professional dental technologists, who have the ability to work reflectively within the contingencies of real-world situations. Reflective journals are widely used assessments for students to reflect on their achievements, interactions with peers, clinicians and patients (where applicable) and elements which need improvement (Table 5). All three acknowledge the importance of providing learners with clear guidance and specific direction on design, fabrication and completion of practical tasks so students will perform better and feel comfortable doing the tasks or assessment (29).

Education of teamwork skills (TL1) is a core component to become a competent professional dental technologist (13). The students at TCD and GU experience learning and working alongside dentistry students through all three years of their study and this provides 'real-life' experience and real patient cases to solve. It is envisaged that this will assist the TCD and GU graduates to exhibit a natural confidence to communicate and cooperate within the OHCT on graduation and have greater knowledge of their role (30) within the team and thus enhance patient care outcomes. Developing teamwork skills is difficult at OAUC, because dentistry 
students are at another institution, therefore students learn through simulated patient cases. Perhaps the higher assessment scores by TCD and GU are due to the exposure to real-life cases. It may be harder to motivate students to reach the same level if the cases are always simulated.

The different scoring/assessment systems between the institutions were resolved into one agreed percentage range (see Appendix 1) to achieve the second objective. The benchmarked assessment strategies were explicit and varied among the three institutions, and directly related to the learning outcomes. It is fundamental for students to know the intended learning outcomes and the assessment criteria required to achieve success (29).

\section{Enhancing the portability of qualifications}

A direct outcome of attaining consistency and transparency of curricula is enhancing opportunities of a portable qualification through ECTS/ CP equivalence. It offers opportunities for student exchange and flexibility for future study. It allows for the mobility of qualifications, better prepares graduates for international registration assessment. Development of guidelines (set of recommendations) to promote collaborative partnerships, offering opportunities for staff exchange and sharing of resources may guide others in the process to establish international consistency. These guidelines (Appendix 2) satisfy the third objective of this study.

A limitation of this study is the absence of statistical power calculation which could have been applied to determine the minimum sample size to observe statistically significant differences. Furthermore the modest number of students that were assessed on what they could 'do' or 'apply' not what they 'know' through comprehension to synthesis of knowledge. Only practical skills were assessed in this study. The higher percentage of hours OAUC allocates to theoretical learning (see table 3) may mean these students gain a deeper theoretical knowledge of the elements in the dental technology curriculum compared with TCD and GU students. However this would require clarification with further research.

\section{CONCLUSION}

Norway, Ireland and Australia have different governing systems and allocation of resources. Each country has varying demands for oral prosthetics, which is reflected in individual curricula of the dental technology programs. A collaborative partnership 
comprising OAUC, TCD and GU, led to enhancement of existing programs by improving: assessment strategies and moderation processes in the field of dental technology education. The outcome from this alliance contributes to international consistency that will expand accessibility, portability and transparency of the graduates' knowledge, skills and abilities which could result in graduates partaking in post graduate studies in clinical dental technology or research higher degrees. Sharing of this nature is particularly significant when graduates are transitioning from a primarily skill based approach to a professional orientation to their work. A significant result is the development of the 'set of recommendations' (Appendix 2), designed to assist others to develop an internationally consistent approach to dental technology or health professional education.

The collaboration and curricula review has created the opportunity for student exchange thus increasing the capacity of the global OHCT. Graduates from one program may well be qualified to apply for future study at the other institution now that the curricula are transparent. It is envisaged that students who experience this assessment might be more confident to seek employment abroad. However further research is required to ascertain the graduate attributes and outcomes.

\section{Acknowledgements}

This project was partly funded by OAUC and GU School of Dentistry and Oral Health internal research grants. The authors are grateful to the previous Head of Department of Radiography and Dental Technology at Oslo and Akershus University College, Agnes Vinorum for her support in establishing our collaborative partnership and encouraging moderation of assessment. The authors acknowledge the valuable contribution of the reviewers. 


\section{REFERENCES}

1. Knight J. Internationalisation brings important benefits as well as risks. International Educator. 2007;16(6):59-62.

2. Norton L. Assessing student learning. In: Fry H, Ketteridge S, Marshal S, editors. A handbook for teaching and learning in higher educaion: Enhancing academic practice 3rd Edn. London: Routledge; 2009.

3. European Commission. European credit transfer and accumulation system (ECTS). Belgium: Office for Official Publications of the European Communities, 2003.

4. Orr S. Assessment moderation: constructing the marks and constructing the students. Assessment \& Evaluation in Higher Educational Administration Quarterly. 2007;32(6):645-56.

5. Sadler DR. Indeterminacy in the use of preset criteria for assessment and grading. Assessment and Evaluation in Higher Education. 2009;34(2):159-79.

6. Queensland Government. Health Practitioner Registration and Other Legislation Amendment Act 2013, Explanatory Notes for SL 2013 Brisbane [cited No. 69]. 3]. Available from:

http://www.legislation.qld.gov.au/LEGISLTN/SLS/RIS_EN/2013/13SL069E.pdf. 7. Council of Australian Governments. Intergovernmental agreement for a National registration and accreditation scheme for the health professionals 2008 [16th April 2015]. Available from:

https://http://www.coag.gov.au/sites/default/files/iga_health_workforce.pdf.

8. Newsome PR. Dental technicians: regulation and quality assurance. Br Dent J. 2011;210(1):25-9.

9. American Dental Association. Dental laboratory technician education and training requirements 2015 [16th April 2015]. Available from:

http://www.ada.org/en/education-careers/careers-in-dentistry/dental-teamcareers/dental-laboratory-technology/education-training-requirements-labtechnician.

10. Living in Canada. Dental Technologist / Technician Salary Canada 2015 [16th April 2015]. Available from: http://www.livingin-canada.com/salaries-fordental-technologists-canada.html.

11. Chaoyi M, Liwei Z, Li Y, Min Z, Haiyang Y. Current status, crisis and trends in Chinese dental technicians. Int Dent J. 2012;62(2):79-83.

12. Christensen GJ, Yancey W. Dental laboratory technology in crisis. The challenges facing the industry. Journal American Dental Association. 2005;136(5):653-5.

13. Evans JL, Henderson AJ, Johnson NW. The future of education and training in dental technology: Designing a dental curriculum that facilitates teamwork across the oral health professions. Br Dent J. 2010;208(5):227-30.

14. Anderson VR, Pang LCY, Aarts JM. New Zealand dental technicians and continuing education: findings from a qualitative survey. $\mathrm{N} Z \mathrm{Z}$ Dent J. 2012;108(2):47-54.

15. European Commission and Australian Department of Education, Employment and Workplace Relations. Study on the (potential) role of qualifications frameworks in supporting mobility of workers and learners Joint EU-Australia Study. Brussels: 2011.

16. European Commisssion. European Qualification Framework 2013 [23rd September 2013]. Available from: http://ec.europa.eu/eqf/home_en.htm. 
17. National Qualifications Authority of Ireland. Referencing of the Irish National Framework of Qualifications (NFQ) to the European Qualifications Framework for Lifelong Learning. Dublin: 2009 Contract No.: 19th August 2013. 18. General Dental Council. Developing the dental team: 2nd Edn (Interim) London2009 [9th Decmeber 2014]. Available from: http://www.gdcuk.org/Newsandpublications/Publications/Publications/DTTsecondedition $1 \% 5$ B1\%5D.pdf.

19. Australian Qualifications Framework Council. Australian Qualifications Framework 2nd Edition. Adelaide: 2013 23rd June 2013. Report No.: Contract No.: 10th November 2013.

20. Norwegian Agency for Quality Assurance in Education. The Norwegian qualifications framework for lifelong learning (NQF) Oslo2011 [3rd July 2014]. Available from:

http://www.nokut.no/Documents/NOKUT/Artikkelbibliotek/Norsk_utdanning/ NKR/20140606_Norwegian_Qualifications_Framework.pdf.

21. European Commission. The European Qualifications Framework (EQF), Education and Training 2012 [2nd September 2013]. Available from: http://ec.europa.eu/education/lifelong-learning-policy/eqf_en.htm. 22. O'Keefe M, Henderson A, Pitt R. Learning and teaching academic standards project: Health, Medicine and Veterinary Science Sydney: Department of Education, Employment and Workplace Relations, Australian Learning and Teaching Council, ; 2011 [9th December 2014]. Available from: http://disciplinestandards.pbworks.com/w/file/fetch/52723773/altc_standard s_HMVS_210611.pdf.

23. Stufflebeam DL, Shinkfield AJ. Systematic evaluation: A self-instructional guide to theory and practice. Boston: Kluwer-Nijhoff; 1985.

24. Sadler DR. Grade integrity and the representation of academic achievement. Studies in Higher Education. 2009;34(7):807-26.

25. Schon DA. The reflective practitioner: How professionals think in action. London: Temple Smith; 1983.

26. Ramsden P. Learning to teach in higher education $2^{\text {nd }}$ Ed. New York: Rutledge Farmer; 2003.

27. Manogue M, McLoughlin J, Christensen C, Delap E, Lindh C, SchoonheimKlein M, et al. Curriculum structure, content, learning and assessment in Euorpean undergraduate dental education - update 2010. Eur J Dent Educ. 2011;15(3):133-41.

28. DePaola DP, Slavkin HC. Reforming dental health professions education: A white paper. J Dent Educ. 2004;68(11):1139-50.

29. Bell A, Mladenovic R, Price M. Students' perceptions of the usefulness of marking guides, grade descriptors and annotated exemplars. Assessment \& Evaluation in Higher Education. 2012;38(7):769-88.

30. Evans JL, Henderson AJ, Johnson NW. Interprofessional learning enhances knowledge of roles but is less able to shift attitudes: a case study from dental education. Eur J Dent Educ. 2012;16(4):239-45. 